\title{
Non-existence of market-clearing wages when the output market is imperfectly competitive
}

\author{
Leo Kaas ${ }^{\mathrm{a}, *}$, Paul Madden ${ }^{\mathrm{b}}$ \\ ${ }^{a}$ Department of Economics, University of Vienna, Hohenstaufengasse 9, 1010 Vienna, Austria \\ ${ }^{\mathrm{b}}$ School of Economic Studies, Manchester University, Manchester M13 9PL, UK
}

\begin{abstract}
In a sector in which oligopolistic firms face a sector-specific labour supply constraint, there may be no marketclearing wage. Instead, at some wages, there can be two equilibria, one with involuntary unemployment and one with unfilled vacancies.
\end{abstract}

Keywords: Involuntary unemployment; Imperfect competition; Multiple equilibria

JEL classification: D43; E24

\section{Introduction}

The consequences for labour markets of imperfect competition in output markets have been extensively studied; relevant surveys are Dixon and Rankin (1994); Silvestre (1993, 1995). A recurrent question in the existing literature is whether, with imperfect competition in the product market, labour demand stays below labour supply at all positive wages. Such an outcome requires that marginal revenue becomes negative at a sufficiently low output level, or, equivalently, that output demand is sufficiently inelastic. Whilst the seminal paper of Hart (1982) excludes this possibility by an assumption on the marginal revenue curve, Dehez (1985); Silvestre (1990) show that such involuntary unemployment at all positive wages can indeed occur in Hart's model. This literature has been refined and extended by Schultz (1992); d'Aspremont et al. (1991); Kaas (1998); Lasselle and Svizzero (2001). Thus there are a

\footnotetext{
* Corresponding author. Fax: +43 142779374.

E mail addresses: leo.kaas@univie.ac.at (L. Kaas), Paul.Madden@man.ac.uk (P. Madden).
} 
number of results which show how there may be no positive wage clearing the labour market, competitive wage adjustment forcing wages to zero ${ }^{1}$.

In this paper we also develop a model of labour market disequilibrium combined with imperfectly competitive output market equilibrium. The decisive, differentiating features of our model are that our (single sector) oligopolists face a sector-specific labour supply constraint ${ }^{2}$, and that signalling labour demand involves both job creation costs and rationing when there is aggregate excess labour demand in the sector. Indeed we assume a sufficiently elastic output demand function which precludes the phenomenon of the first paragraph. Instead our model generates a profit function kink which leads to the non-existence of a wage that clears the labour market, and the existence of some wages where there are two disequilibrium outcomes, one with involuntary unemployment and one with unfilled vacancies. Attempts to clear our labour market by competitive wage adjustment would produce a persistent disequilibrium cycle.

Whereas the above-mentioned literature considers general equilibrium models of oligopolistic or monopolistic competition, our paper focuses on the partial equilibrium of a single sector of an economy, where output demand and labour supply schedules are not explicitly derived from utility maximising workers/consumers. However, it is straightforward to integrate our model in a multi-sector general equilibrium model in the spirit of Blanchard and Kiyotaki (1987) in which a continuum of consumers demand consumption goods from all sectors, but supply labour in only one sector, as we remark below.

Section 2 introduces the model, Section 3 contains results and Section 4 concludes. Lengthier proofs are contained in an Appendix available from the authors on request.

\section{The model}

We consider a sector of an economy in which $n \geq 2$ identical firms produce a homogenous output good from inputs of homogenous sector-specific labour under unit constant returns, $y_{i}=\ell_{i}, i=1, \ldots n$. Firms face an output demand function whose inverse we denote by $P\left(y_{1}+\ldots+y_{n}\right)$ and which has constant elasticity $\rho, \rho \in(0, n)$. On the labour market, firms face a common labour supply $L$, and they take the money wage $w$ as given ${ }^{3}$.

The usual argument for existence of a positive market-clearing wage with a sufficiently elastic output demand and sector-specific labour goes as follows: when there is Cournot competition between $n>1$ firms facing a demand function of elasticity $1 / \rho$ with $\rho \in(0, n)$, labour demand is a function of the wage of elasticity $1 / \rho$. Hence, as the wage tends to zero, labour demand tends to infinity, and vice versa, so the labour market must clear at some positive wage. However, this argument is problematic since firms ignore the input supply constraint in the standard Cournot game. We assume instead that firms

1 Strictly speaking, the labour market is in equilibrium at zero wage at which workers are indifferent between being employed or not.

2 There is empirical evidence suggesting that industry specificity contributes more to the wage profile than firm specificity, thus providing insights about the importance of industry specific human capital (see Neal, 1995; Parent, 2000).

3 Alternatively consider a general equilibrium model. In each of a continuum of sectors, a single good is produced by $n$ firms, and a continuum of workers of mass $L$ each supply one unit of labour inelastically. Consumers have CES preferences over the continuum of goods with substitution elasticity $\rho$. In each sector, output demand has constant elasticity $\rho$ and $L$ is the labour supply. Our single sector equilibria correspond to symmetric equilibria in such a model. A related model (without our non existence feature) is found in Kaas and Madden (2004). 
simultaneously decide about the number of jobs they create, anticipating that labour demand may be rationed whenever the total number of jobs exceeds labour supply.

Specifically, firms create a number of jobs $J_{i} \geq 0, i=1, \ldots, n$, and they pay a cost $c>0$ for each job opening. As in the literature on labour market search (see e.g. Pissarides, 2000), these costs can be thought of as recruitment costs (capturing costs of advertising and interviewing) that are incurred with every job. After firms create jobs, workers and jobs are matched according to a frictionless and symmetric matching technology. Thus, the fraction of vacancies that are filled is the same for every firm, and it equals one whenever the number of workers exceeds the number of jobs. Hence, actual employment levels at the $n$ firms are

$$
\ell_{i}=J_{i} \min \left(1, \frac{L}{J_{1}+\ldots+J_{n}}\right), \quad i=1, \ldots, n .
$$

With the workers matched to jobs, firms produce output to be sold at the market price $P\left(\ell_{1}+\ldots+\ell_{n}\right)$. The firms therefore make profits

$$
\pi^{i}\left(J_{1}, \ldots, J_{n}\right) \equiv\left(P\left(\ell_{1}+\ldots+\ell_{n}\right) \quad w\right) \ell_{i} \quad c J_{i}, \quad i=1, \ldots, n,
$$

where the employment levels $\ell_{i}$ follow from the matching technology Eq. (1). We are interested in fixwage equilibria $J_{1}=\ldots=J_{n}=J$ which are a symmetric pure strategy Nash equilibria of the one-stage game in which firms create jobs simultaneously to maximise their profits at the given wage $w$. By focusing on a symmetric equilibrium, we consider the best response problem of firm 1 only. Denote by $\pi\left(J_{1}, J\right)=\pi^{1}\left(J_{1}, J, \ldots, J\right)$ the profit of firm 1 provided that firms $2, \ldots, n$ offer the same number of jobs $J$. When the total number of jobs is less than the number of workers, there is unemployment, and firm 1's profit function is

$$
\pi\left(J_{1}, J\right)=\pi^{\mathrm{U}}\left(J_{1}, J\right) \equiv\left(P\left(J_{1}+\left(\begin{array}{ll}
n & 1
\end{array}\right) J\right) \quad w \quad c\right) J_{1}, \quad \text { if } J_{1}+\left(\begin{array}{ll}
n & 1
\end{array}\right) J \leq L .
$$

Hence, whenever there is unemployment, firms face Cournotian profit functions with unit costs equal to $w+c$. On the other hand, when the total number of jobs exceeds the number of workers, there are excess vacancies, and firm 1's profit function is

$$
\pi\left(J_{1}, J\right)=\pi^{\mathrm{V}}\left(J_{1}, J\right) \equiv(P(L) \quad w) L \frac{J_{1}}{J_{1}+\left(\begin{array}{ll}
n & 1
\end{array}\right) J} \quad c J_{1}, \quad \text { if } J_{1}+\left(\begin{array}{ll}
n & 1
\end{array}\right) J \geq L .
$$

When there are excess vacancies, aggregate employment and output equal $L$, irrespective of the number of jobs at firm 1. Hence, firm 1 takes the output price $P(L)$ as given, but competes with the other firms for the number of workers, which are allocated according to the proportional rationing scheme. The first derivatives of these two profit functions w.r.t. $J_{1}$ are

$$
\begin{aligned}
& \pi_{1}^{\mathrm{U}}\left(J_{1}, J\right)=P\left(J_{1}+\left(\begin{array}{ll}
n & 1
\end{array}\right) J\right)\left(\begin{array}{lll}
1 & \rho \frac{J_{1}}{J_{1}+\left(\begin{array}{ll}
n & 1
\end{array}\right) J}
\end{array}\right) \quad w \quad c, \\
& \pi_{1}^{\mathrm{V}}\left(J_{1}, J\right)=(P(L) \quad w) L \frac{\left(\begin{array}{ll}
n & 1
\end{array}\right) J}{\left(J_{1}+\left(\begin{array}{ll}
n & 1
\end{array}\right) J\right)^{2}} \quad c
\end{aligned}
$$


Both $\pi^{\mathrm{V}}$ and $\pi^{\mathrm{U}}$ are strictly concave in $J_{1}$. However, the composite profit function $\pi$ needs not be concave, but has a kink at the transition from unemployment to excess vacancies. There are three types of potential fixwage equilibria $J_{1}=J$ : a market-clearing equilibrium in which $J=L / n$, an unemployment equilibrium with $J<L / n$, and a vacancy equilibrium with $J>L / n$. We will now explore the conditions under which these equilibria exist.

\section{Fixwage equilibria}

We are first interested in the existence of a market-clearing equilibrium. If $w$ is a market-clearing wage, there must be an equilibrium $J_{1}=J=L / n$. Since the profit function of firm 1 has a kink at $\left(J_{1}, J\right)=(L / n, L / n), J_{1}=L / n$ is a best response to $J=L / n$ if and only if $\pi_{1}^{\mathrm{U}}(L / n, L / n) \geq 0 \geq \pi_{1}^{\mathrm{V}}(L / n, L / n)$ (because each of the two profit functions is differentiable and concave). Using Eqs. (2) and (3), these conditions are equivalent to

$$
P(L)\left(1 \quad \frac{\rho}{n}\right) \quad c \geq w \geq P(L) \quad \frac{n}{n \quad 1} c
$$

Hence, these two conditions can be satisfied only if

$$
c \geq P(L) \rho \frac{n \quad 1}{n}
$$

If Eq. (5) is not satisfied, there exists no market-clearing equilibrium. When job creation costs are low relative to the degree of output market power (measured by the inverse of the output demand elasticity $\rho$ ), the profit function kinks upwards at the transition from unemployment to excess vacancies. Hence, when firms $i>1$ each create $J=L / n$ jobs, firm 1 either finds profitable upward deviations to some $J_{1}>L / n$ (when the wage is low) or to some $J_{1}<L / n$ (when the wage is high), or to both (for intermediate wages). Consequently, no market-clearing equilibrium wage exists ${ }^{4}$. Conversely, if Eq. (5) is satisfied, the interval of wages in Eq. (4) is non-empty. Thus, each of these wages is a market-clearing equilibrium wage because $J_{1}=L / n$ is a best response to $J=L / n$.

\section{Proposition 1.}

(a) If Eq. (5) is satisfied (i.e. job creation costs are high), there exists a market clearing equilibrium at any wage w satisfying Eq. (4).

(b) If Eq. (5) is not satisfied (i.e. job creation costs are low), there exists no market clearing equilibrium at any wage.

\footnotetext{
${ }^{4}$ It can also be shown that the existence of an asymmetric pure strategy market clearing equilibrium requires a condition, which is even stronger than Eq. (5).
} 
The non-existence result is due to the upward kink (or non-concavity) of profit functions. A further consequence of this non-concavity is a discontinuity of best response functions. Specifically, if Eq. (5) is satisfied, best response functions are continuous, and, as we will show in the following propositions, there exists a unique equilibrium at any given wage which depends continuously on the wage. On the other hand, if Eq. (5) is not satisfied, best response functions are discontinuous. As a result, there exist multiple fixwage equilibria for some wages, and the equilibrium correspondence is discontinuous.

We present next the results on the existence of unemployment equilibria.

\section{Proposition 2.}

(a) If Eq. (5) is satisfied, there exists a unique unemployment equilibrium $J<L / n$ for all $w>P(L)\left(1-\frac{\rho}{n}\right)-c$ which is given by $P(n J)\left(1-\frac{\rho}{n}\right)=c+w$, and there exists no unemployment equilibrium for all other wages.

(b) If Eq. (5) is not satisfied, there exists

$$
w^{\mathrm{U}} \in\left(P(L)\left(\begin{array}{ll}
1 & \frac{q}{n}
\end{array}\right) \quad c, P(L) \quad c \frac{n}{n \quad l}\right)
$$

such that there exists a unique equilibrium for all $w \geq w^{U}$, and there exists no unemployment equilibrium for all $w<w^{U}$.

Part (a) of this Proposition refers to the well-behaved case of continuous best response functions. In this case, unemployment tends to zero as the wage falls to the highest market-clearing wage $w=$ $P(L)\left(\begin{array}{ll}1 & \frac{\rho}{n}\end{array}\right) \quad c$. In part (b), best response functions are discontinuous. As the wage falls below the lowest unemployment wage $w^{\mathrm{U}}$, it becomes profitable for firms to create a large number of jobs, so as to create an excess demand for labour and to attract workers from the other firms. When the firms do so, however, they suffer a decline in the output price (for output increasing to the full employment output) and they increase their total costs of job creation. But when $c$ is low relative to the degree of market power, the gains from attracting workers are large relative to both the costs of creating excess vacancies and to the profit loss due to the fall in output price.

A similar picture emerges for the final case of vacancy equilibria. For high job creation costs, a vacancy equilibrium exists for all wages up to $P(L) \quad c \frac{n}{n 1}$ at which excess vacancies become zero. On the other hand, for low job creation costs (relative to the degree of market power), a vacancy equilibrium only exists up to a wage $w^{\mathrm{V}}$ above which firms prefer to create few jobs and unemployment, so as to gain from the increase in output price.

\section{Proposition 3.}

(a) If Eq. (5) is satisfied, there exists a unique vacancy equilibrium

$$
J=\frac{\left(\begin{array}{ll}
n & 1
\end{array}\right)(P(L) \quad w}{n c} \frac{L}{n}
$$

for all $w<P(L)-c \frac{n}{n l}$, and there exists no vacancy equilibrium for all other wages. 
(b) If Eq. (5) is not satisfied, there exists

$$
w^{\mathrm{V}} \in\left(P(L)\left(\begin{array}{ll}
1 & \frac{\rho}{n}
\end{array}\right) \quad c, P(L) \quad c \frac{n}{n \quad l}\right)
$$

such that there exists a unique vacancy equilibrium for all $w \leq w^{V}$, and there exists no vacancy equilibrium for all $w>w^{V}$.

It is now clear from parts (a) of Propositions 1-3 that there is a unique fixwage equilibrium at any wage when Eq. (5) is satisfied. If Eq. (5) is not satisfied, a fixwage equilibrium would not exist at some wages if the lowest unemployment wage exceeded the highest excess vacancy wage, i.e. if $w^{\mathrm{U}}>w^{\mathrm{V}}$. However, existence of a fixwage equilibrium can be guaranteed at all wages. As the proof of Proposition 4 reveals, best response functions can have at most one discontinuity which must be an upward jump from an unemployment best response $J_{1}<L \quad\left(\begin{array}{ll}n & 1\end{array}\right) J$ to an excess vacancy best response $J_{1}>L \quad\left(\begin{array}{ll}n & 1\end{array}\right) J$ as $J$ increases, and the best response is a continuous and concave function otherwise. This behaviour of best response functions leads to the existence of at least one symmetric pure strategy equilibrium at any wage (hence implying $w^{\mathrm{U}} \leq w^{\mathrm{V}}$ ). Moreover, a continuity argument implies that $w^{\mathrm{U}}<w^{\mathrm{V}}$.

Proposition 4. If Eq. (5) is not satisfied, $w^{\mathrm{U}}<w^{\mathrm{V}}$.

Propositions 1-4 are illustrated in Fig. 1 and summarised in the following theorem.

\section{Theorem 1.}

(a) When job creation costs are high, there is a unique fixwage equilibrium at any wage. The equilibrium exhibits unemployment for high wages, excess vacancies for low wages, and market clearing for intermediate wages.

(b) When job creation costs are low, there exists no market clearing equilibrium wage. For high wages, there exists a unique unemployment equilibrium, for low wages there exists a unique equilibrium with excess vacancies, for intermediate wages there exists one equilibrium with unemployment and one with excess vacancies.
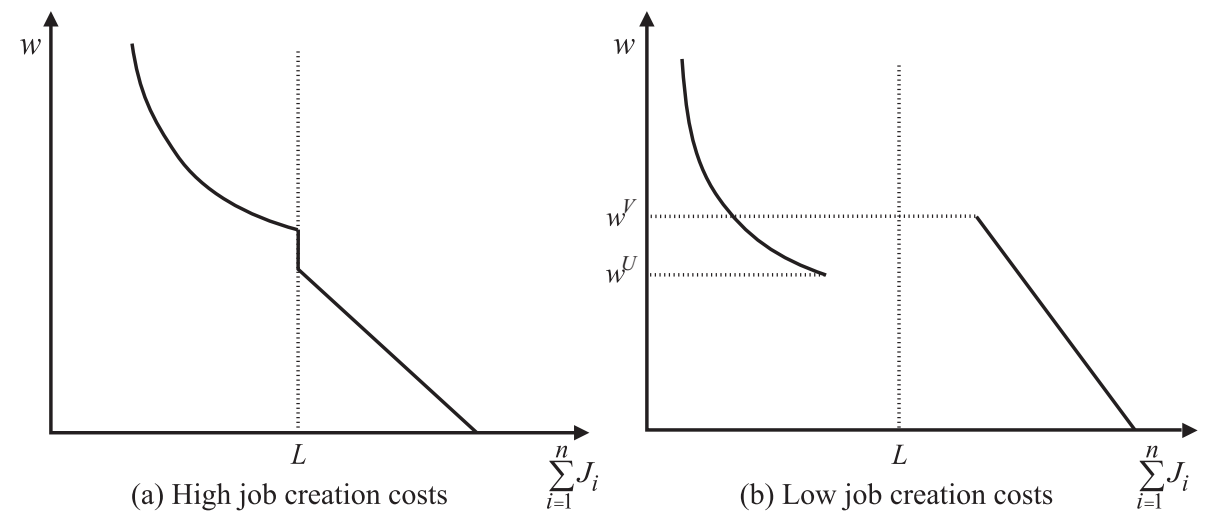

Fig. 1. Labour market disequilibrium. 
Note that, when job creation costs are zero, condition Eq. (5) is not satisfied, and Proposition 1 implies that there exists no market-clearing wage. Proposition 2 remains valid and implies that there are unemployment equilibria for all $w \geq w^{\mathrm{U}}<P(L)$.

However, fixwage equilibria with excess vacancies fail to exist, as the proportional rationing scheme induces firms to drive job openings to infinity whenever the wage is less than $P(L)$ and whenever other firms signal an excess demand for labour. Such overbidding behaviour and failure of existence of fixwage equilibria at given wages are well-known features of manipulable rationing mechanisms (see e.g. Bénassy, 1982). To guarantee existence, some non-manipulability of rationing is required. For instance, if we assume that firms have some capacity level $J>L / n$ so that they cannot credibly attract workers beyond this level, vacancy equilibria at $J=J$ exist for all $w \leq P(L)$ when $c=0$.

\section{Conclusion}

With output market imperfect competition and sector-specific labour, the paper shows how there may be no wage which clears the labour market and a range of wages at which there are two fixwage equilibria, one with involuntary unemployment and one with unfilled vacancies. When a competitive labour market is in disequilibrium, firms and workers have strong incentives to adjust the wage: with excess vacancies, the wage goes up and with unemployment, the wage goes down. Whereas in other literature with persistent involuntary unemployment, such competitive wage adjustment drives the wage to zero, here the wage would permanently fluctuate between disequilibrium periods of involuntary unemployment and excess demand for labour.

\section{Acknowledgements}

We are grateful to Harald Uhlig for stimulating remarks, and we thank an anonymous referee for helpful comments. Financial support from the Economic and Social Research Council (UK) under grant L138251030 and from the Austrian Science Fund (FWF) is gratefully acknowledged.

\section{References}

Bénassy, J. P., 1982. The Economics of Market Disequilibrium. Academic Press, New York.

Blanchard, O., Kiyotaki, N., 1987. Monopolistic competition and the effects of aggregate demand. American Economic Review $77,647666$.

d'Aspremont, C., Dos Santos Ferreira, R., Gérard Varet, L., 1991. Imperfect competition, rational expectations, and unemployment. In: Barnett, W., Cornet, B., d'Aspremont, C., Gabszewicz, J., Mas Colell, A. (Eds.), Equilibrium Theory and Applications: Proceedings of the Sixth International Symposium in Economic Theory and Econometrics. Cambridge Uni versity Press, Cambridge, pp. 353381.

Dehez, P., 1985. Monopolistic equilibrium and involuntary unemployment. Journal of Economic Theory 36, 160165.

Dixon, H., Rankin, N., 1994. Imperfect competition and macroeconomics: a survey. Oxford Economic Papers 46, 171199.

Hart, O.D., 1982. A model of imperfect competition with Keynesian features. Quarterly Journal of Economics $97,109138$.

Kaas, L., 1998. Multiplicity of Cournot equilibria and involuntary unemployment. Journal of Economic Theory 80, 332349.

Kaas, L., Madden, P., 2004. Imperfectly competitive cycles with Keynesian and Walrasian features. Forthcoming in European Economic Review. 
Lasselle, L., Svizzero, S., 2001. The impossibility of underemployment with more than one sector. Oxford Economic Papers 53, 157165.

Neal, D., 1995. Industry specific human capital: evidence from displaced workers. Journal of Labor Economics 13, 653677.

Parent, D., 2000. Industry specific capital and the wage profile: evidence from the National Longitudinal Survey of Youth and the Panel Study of Income Dynamics. Journal of Labor Economics 18, 306323.

Pissarides, C., 2000. Equilibrium Unemployment Theory, 2nd ed. The MIT Press, Cambridge, MA.

Schultz, C., 1992. The impossibility of involuntary unemployment in an overlapping generations model with rational expect ations. Journal of Economic Theory 58, 6176.

Silvestre, J., 1990. There may be unemployment when the labour market is competitive and the output market is not. The Economic Journal 100, 899913.

Silvestre, J., 1993. The market power foundations of macroeconomic policy. Journal of Economic Literature 31, 105141.

Silvestre, J., 1995. Market power in macroeconomic models: new developments. Annales d'Économie et de Statistique 37/38, 319356. 